\title{
SOCIEDADE E CONHECIMENTO: novas \\ tecnologias e desafios para a produção de conhecimento nas Ciências Sociais
}

\author{
Maíra Baumgarten* \\ Alex Niche Teixeira** \\ Gilson Lima***
}

\begin{abstract}
Resumo: Este artigo debate algumas questões ligadas às relações entre sociedade e conhecimento, abordando as temáticas da sociedade da informação e da interdisciplinaridade (redes), associadas aos avanços nas tecnologias de informação e comunicação. A partir dessas relações são discutidos, especificamente, o desenvolvimento de metodologias informacionais e as possibilidades e desafios que daí emergem para a pesquisa e a produção de conhecimento nas Ciências Sociais e para a compreensão e o desenvolvimento de redes de informação e de saberes.
\end{abstract}

Palavras-chave: tecnologias de informação, conhecimento e informação, metodologias informacionais

As Ciências Sociais enfrentam grandes desafios decorrentes das profundas reestruturações econômicas, organizacionais e culturais presentes na atual configuração contemporânea da sociedade.

\footnotetext{
* Doutora em Sociologia, professora do Departamento de Educação e Ciências do Comportamento da Universidade Federal de Rio Grande e do Programa de Pós-Graduação em Sociologia da Universidade Federal do Rio Grande do Sul (UFRGS), e coordenadora do Centro de Estudos e Difusão de Conhecimentos, Inovação e Sustentabilidade (CEDCIS).

** Doutorando em Sociologia na UFRGS e membro do Grupo de Pesquisa Violência e Cidadania.

*** Doutor em Sociologia pela UFRGS, professor e pesquisador do mestrado em Reabilitação e Inclusão do Centro Universitário IPA em Porto Alegre. Colaborador do Núcleo de Violência e Cidadania do Programa de Pós-Graduação em Sociologia pela UFRGS.
}

Artigo recebido em $1^{\circ}$ dez. 2006 e aprovado em 18 maio 2007. 
No contexto da emergência de novas formas produtivas e societárias que caracterizam o que alguns denominam "sociedade de informação" e outros chamam "sociedade do conhecimento" ou "do aprendizado" (Stehr, 1994; Lastres \& Albagli, 1999), a produção/distribuição de informação e de conhecimento e a redução das desigualdades sociais tornam-se mutuamente indispensáveis. $\mathrm{O}$ conhecimento desempenha, atualmente, papel estratégico, não só para a acumulação econômica, mas também para o funcionamento do próprio Estado e da sociedade. Novas possibilidades e desafios de desenvolvimento (como processo de mudança social), emergem das transformações imateriais que se operam tanto na produção material quanto na produção dos intangíveis (Maciel, 2001).

As mudanças que acompanham a ordem social crescentemente mundializada do século XXI e o forte desenvolvimento das tecnologias de informação e de comunicação (TICs) são, ao mesmo tempo, objeto de estudo das ciências sociais (como parte estratégica da sociedade atual) e elemento central da transformação das suas condições de produzir conhecimentos sobre a sociedade. Ao viabilizarem diferentes possibilidades de registro e de acompanhamento das relações entre atores sociais, as TICs podem alterar significativamente as fontes e formas de geração de indicadores sobre a sociedade, além de facilitar a formação de redes de bancos de dados.

Por outro lado, as redes de produção, disseminação e apropriação de conhecimentos desempenham hoje um papel central na sociedade, tornando estratégica a reflexão sobre as mesmas e sobre as repercussões que trazem para as formas de produção e apropriação de conhecimentos, notadamente para as possibilidades do trabalho inter e transdisciplinar em uma sociedade cada vez mais complexa.

Neste artigo serão abordadas as temáticas da sociedade da informação e da interdisciplinaridade (redes), associadas aos 
avanços nas tecnologias de informação e comunicação e à produção de conhecimentos sobre a sociedade. A partir das relações entre sociedade e conhecimento serão debatidos, especificamente, os novos métodos e técnicas de investigação em Ciências Sociais, baseados nos recentes desenvolvimentos de tecnologias de informação e comunicação, e suas possibilidades para a produção de conhecimento sobre a sociedade e para a compreensão e a criação de redes de conhecimentos e informação.

Em um primeiro momento, serão apresentadas algumas questões sobre as relações entre sociedade, conhecimento e método; a seguir, o uso de programas computacionais em análises qualitativas e algumas de suas implicações na pesquisa social; e, por fim, alguns desafios que se colocam para as ciências sociais a partir das metodologias informacionais.

\section{Complexidade, conhecimento e ação: sociedade, teoria, método}

O ímpeto de conhecer relaciona-se ao impulso para descobrir, desvelar obscuridades, revelar pequenos instantâneos da vida ou grandes painéis da natureza e das sociedades. Miudezas do cotidiano dos seres ou a imensidão espaço-temporal do universo e toda a problemática que medeia esses dois pólos são o objeto dessa busca que está intimamente ligada às pequenas e grandes necessidades humanas e aos nossos desejos de satisfazer carências.

O paradigma da ciência moderna, assentado na razão, na divisão/análise e na máxima "conhecer para controlar", reduziu os problemas e suas respostas a modelos para a ação transformadora sobre a natureza e controladora da sociedade, produzindo conhecimentos disciplinares e com alto nível de especialização. Separar e reduzir têm sido máximas do paradigma moderno. 
Entretanto, natureza e sociedade nunca deixaram de ser complexas e o mundo atual é a expressão dessa complexidade - os problemas que se nos apresentam são multidimensionais e as contradições se avolumam. O ser humano, por suas próprias mãos alienadas da natureza (que não deixa por isso de integrar), passou a ameaçá-la de forma perigosa para a sua própria espécie e para todas as outras. Os laços de solidariedade humana tornam-se frágeis, desfazem-se e contradições irredutíveis emergem no cotidiano natural e social (Baumgarten, 2006).

As formas assumidas pelo desenvolvimento capitalista, em escala global, criam grandes tensões, que originam diversas demandas de políticas e de instrumentos de regulação social e econômica, os quais, por sua vez, requerem conhecimentos sobre os problemas, necessidades e potencialidades das diferentes coletividades formadas por distintos atores sociais.

Como conhecer e como agir nessa realidade? Como perceber as tantas bifurcações que o devir contém, seus feixes de possibilidades? Como escolher caminhos? A perspectiva da complexidade tem sido apontada como alternativa para lidar com as incertezas do mundo contemporâneo.

Mas o que é a perspectiva da complexidade? Para além de ser um conhecimento que envolve problemas e diálogos multi, inter e transdisciplinários, esse ponto de vista parte de uma sociedade e natureza complexas, que lançam o desafio do desenvolvimento de modos de conhecer menos reducionistas (Baumgarten, 2006).

Tanto o desenvolvimento do capitalismo como o da ciência moderna prosperaram a partir de uma relação de interdependência entre a lógica mercantil do primeiro e os pressupostos lineares da segunda. E, também, podem ser creditadas ao racionalismo cartesiano muitas das conseqüências indesejadas que se têm produzido ao longo dos últimos dois séculos. Por outro lado, da crítica da ciência moderna 
surgem/ressurgem perspectivas não lineares que consideraram novas conexões e/ou saberes entre consciência e existência, sujeito/ objeto, homem/natureza, na busca por compreender a sociedade contemporânea (Virgínio, 2006).

Os limites do conhecimento disciplinar se fazem sentir especialmente quando os problemas a resolver envolvem objetos complexos, como a sociedade, e quando a redução da complexidade impede o desvelamento e a solução do problema. O paradigma da ciência moderna sempre se demonstrou inadequado para a análise da sociedade e seus problemas, seja pela problemática da relação sujeito/objeto, seja pela sua linearidade e determinismo.

Um dos principais focos do debate epistemológico em ciências sociais tem sido a questão da objetividade do conhecimento. De um lado, a reivindicação positivista de objetividade em geral, baseada no princípio da existência de uma relação de exterioridade entre o sujeito conhecedor e a realidade, realidade essa que contém racionalidade, ordenação, sendo por isso mesmo cognoscível, desde que o sujeito se arme de meios adequados.

De outro lado, existe a relativização das possibilidades de objetividade trazida pelo debate crítico histórico-hermenêutico e pelas abordagens fenomenológicas, com sua ênfase na compreensão e na importância dos contextos de vida, da linguagem e do sentido. O ponto de partida aqui é que o mesmo fenômeno muda de sentido em diferentes situações. O mundo social é visto como um mundo construído com significados e símbolos, o que implica a busca dessa construção e seus significados. A predição e o controle da tradição das ciências naturais não são encarados como possíveis na vida social, instância em que a causa está mediatizada por sistemas de símbolos que nela interferem (ou podem interferir) a cada momento (Santos \& Baumgarten, 2005).

No paradigma compreensivo os fatos sociais não são "coisas", mas sim interpretações criadas pelos seres humanos, relativamente 
às coisas, aos outros seres humanos e às relações entre estes últimos (Lessard-Hébert et al., 1994). Não sendo a sociedade um organismo natural e sim um artefato humano, para compreendê-la é preciso investigar o significado dos símbolos sociais e não explicar as realidades sociais "externas". Nessa perspectiva, o ponto de vista “objetivo" ou "neutro", recomendado pelo positivismo, é uma impossibilidade metodológica (Herman, 1983).

O que se pretende, retomando esse debate, é ressaltar a estreita e indissociável vinculação entre teoria, método e técnicas como précondição para refletir sobre as possibilidades criadas pelas novas metodologias informacionais para a pesquisa em ciências sociais.

O método parte de um corpo teórico integrado. Envolve as técnicas, dando-lhes sua razão, perguntando-lhes sobre suas possibilidade e sobre as limitações que trazem ou podem trazer às teorias a que servem, no trabalho sobre seu objeto (Bachelard, 1984, 1990).

O conhecimento científico é uma categoria histórica e, como tal, é movimento em contínua evolução que condiciona a cognoscibilidade ao desenvolvimento dos instrumentos físicos e da inteligência histórica dos cientistas individuais (Gramsci, 1978). Nenhuma ciência se apresenta como puro sistema de objetividade e sim decorre sempre de práticas, técnicas hipóteses, num incessante trabalho de revisão dos conhecimentos. Há níveis de objetividade, há acordos de grupos ideologicamente dessemelhantes quanto aos mesmos conhecimentos teóricos, mas há também processos historicamente condicionados que permitem que cada ciência se desenvolva (Védrine, 1977).

No século XXI vivemos, como sugere Sousa Santos (2000), num tempo atônito que projeta sombras do passado e do futuro, vivemos num período em que um novo paradigma de ciência, decorrente das descobertas revolucionárias oriundas principalmente 
da teoria da relatividade, da mecânica quântica, da teoria do caos, da geometria dos fractais, da auto-organização, da complexidade organizacional, fez crescer a desconfiança sobre a objetividade, as certezas e determinismos inerentes à mecânica newtoniana, sem dúvida, o principal ícone da ciência clássica e do modelo de ciência nela recorrente (Gaya \& Torres, 2003).

$\mathrm{Na}$ transição paradigmática que ora vivemos há que desenvolver o pensamento complexo e relacional. Do ponto de vista da epistemologia complexa, estamos trabalhando em um movimento por um realismo relacional, relativo e múltiplo (Morin, 1986).

As ciências modernas são o resultado emergente, situado na intersecção e articulação dinâmica de atores humanos, entidades vivas não humanas, materiais de vários tipos, instrumentos, competências diversas, recursos institucionais e financeiros. Tanto o conhecimento, como os objetos tecnológicos são construídos no quadro daquilo que se pode designar ecologias de práticas (Nunes, 2003).

A idéia da existência de um duplo condicionamento entre produção de conhecimento científico e sociedade indica a importância de se refletir sobre as relações entre as transformações sociais e os métodos para refletir sobre a sociedade. As transformações sociais recentes e as tecnologias de informação e comunicação que embasam novas metodologias vêm alterando significativamente o fazer científico em Ciências Sociais, apontando para uma ecologia de saberes (Santos, 2006).

As ciências sociais têm incorporado, em si, diversas práticas de investigação interdisciplinar(importação, cruzamento, convergência, entre outras) e, cada vez mais, parecem estar ocorrendo mudanças nessas ciências provocadas pelos "impactos" das tecnologias da informação, em vários âmbitos, cujos resultados poderão produzir novos modos de observar, de apreender e de explicar o mundo (Santos \& Baumgarten, 2005). 
A seguir discutiremos algumas implicações das novas tecnologias informacionais na pesquisa social.

\section{Novos desenvolvimentos em tecnologias informacionais e a pesquisa social}

As metodologias informacionais constituem a novidade no atual momento teórico e são ainda pouco utilizadas na Sociologia contemporânea. A linguagem comunicacional da atualidade carrega o desafio da transição paradigmática e, em particular os dilemas de uma sociedade capitalista em que a tecnociência, ${ }^{1}$ inserida no processo de globalização pode criar novas formas de exclusão e de fragmentação social e, ao mesmo tempo, alternativas de inclusão e inovação social (Santos, 2001; Baumgarten, 2005). Elas são tecnologias intelectuais que:

amplificam, exteriorizam e modificam numerosas funções cognitivas humanas: memória (bancos de dados, hiperdocumentos, arquivos digitais de todos os tipos), imaginação (simulações), percepção (sensores digitais, telepresença, realidades virtuais), raciocínios (inteligência artificial, modelização de fenômenos complexos). (Levy, 1999, p.157).

Em recente estudo sobre o tema, Tavares dos Santos e Baumgarten (2005) questionam em que medida o uso da tecnologia informacional implica, não só um avanço na análise de dados de diferentes tipos, mas, também, em efeitos sobre a estruturação dos modelos cognitivos com os quais costumamos trabalhar.

Com a revolução da microeletrônica e o desenvolvimento das ciências da computação, nos anos 80 , o tratamento computacional de informações passou a se disseminar, sobretudo pelo acesso ampliado aos microcomputadores, viabilizando o desenvolvimento da pesquisa qualitativa auxiliada por computador. 
No início da década de 80, começaram a circular, no mundo anglófono, as primeiras versões de programas de computador com a finalidade de auxiliar o processo de análise de dados qualitativos. Programas como TheEthnograph,Alceste,Kwalitan,HyperResearch, Winmax, Atlas/TI e NUD*IST, ainda com uma interface pouco amigável, passaram a ser utilizados particularmente por entusiastas pesquisadores das ciências sociais e foram agrupados sob a sigla CAQDAS (Computer Aided Qualitative Data Analisys Softwares). ${ }^{2}$ Colocava-se, para a análise de informações não numéricas e de material discursivo, a idéia de um suporte informatizado comparável àquilo que já antes existia para o tratamento estatístico de dados quantitativos (Kelle, 1999).

No Brasil, o contato com estas ferramentas informacionais deu-se somente a partir da metade dos anos 90, quando os programas já haviam passado por aperfeiçoamentos significativos mediante experiências de utilização em situações práticas de pesquisa. Este, a propósito, consistiu em um diferencial importante do programa NUD*IST Vivo, ${ }^{3}$ que foi e tem sido a principal porta de entrada dos pesquisadores brasileiros para o mundo da análise de dados qualitativos auxiliado por computador: o programa foi desde o início desenvolvido a partir da intervenção direta de pesquisadores orientados por métodos e técnicas de investigação e análise do campo das ciências humanas (Richards, 2006a; Mangabeira, Lee \& Fielding, 2001).

As primeiras exposições e cursos desenvolvidos em instituições de ensino superior, em reuniões de divulgação científica, como os Encontros da ANPOCS ou nos Congressos da Sociedade Brasileira de Sociologia, costumavam despertar, em alguns pesquisadores, posições peculiares, aparentemente opostas, mas que acabavam por criar obstáculos junto à coletividade científica no sentido de uma utilização conseqüente dos programas de análise de dados qualitativos. 
De um lado, a desconfiança, geralmente por parte de pesquisadores mais experientes, apoiada no argumento de que estes programas afastariam o investigador da realidade, uma vez que gerariam um distanciamento esterilizante em relação aos dados. Além disso, tornariam a análise engessada, presa aos protocolos informacionais disponibilizados, inibindo a criatividade metodológica.

Há quase uma década, Barry (1998) já tematizava sobre esta perspectiva, salientando a idéia, igualmente equivocada, de que estes programas forçariam a analisar os dados qualitativos de forma quantitativa, ocasionando assim uma homogeneidade entre os métodos de análise de dados.

Em um outro extremo, as primeiras notícias da existência de programas de computador para a análise qualitativa suscitavam um deslumbramento movido pela crença de que o programa era inteligente e automático, bastando alimentá-lo com material empírico para dispor, sem esforço, das análises prontas.

Esta ilusão - que no mais das vezes acompanhava pesquisadores com pouca experiência em pesquisa e métodos -, rapidamente convertia a receptividade fascinada para com o programa em decepção e, conseqüentemente, num obstáculo, exigindo um esforço de conscientização no sentido de que os programas de análise de dados qualitativos não se constituem em oráculo de onde emanam magicamente as respostas aos problemas de pesquisa. Ao contrário, a realidade social é sempre mais complexa do que nossos métodos e nossa capacidade de análise. Explicar fenômenos sociais é sempre um exercício de redução da complexidade social (Lima, 2006, p.170).

No primeiro caso, o receio esteve ligado, em grande medida, a uma resistência natural quanto à utilização do computador como uma ferramenta cotidiana, mesmo para tarefas hoje consideradas 
simples, como a mera edição de textos. Mais do que vencer a barreira do uso dos programas de análise qualitativa, tratava-se de vencer a barreira da incorporação das ferramentas informacionais de um modo geral. E nisto havia também um aspecto material importante, já que os computadores passaram a existir com relativa abundância nas instituições de ensino e pesquisa brasileiras apenas na última metade da década de 90.

Hoje em dia, muitas já são as experiências de grupos de pesquisa, mestrandos e doutorandos, em diversas áreas de conhecimento no Brasil, que utilizaram programas de análise de dados qualitativos em seus estudos. O crescente contato com os programas vem, paulatinamente, afastando noções equivocadas de parte a parte sobre o seu uso e estimulando os pesquisadores tanto no aprendizado de métodos, quanto no aperfeiçoamento e invenção de novas estratégias de análise.

\section{$O$ que fazem e como funcionam esses programas: o caso do NUD*IST}

A sigla que deu nome ao programa NUD*IST auxilia a entender a finalidade dos programas de computador voltados para a análise qualitativa: Non-numerical Unstructured Data Indexing, Searching and Theorizing. Portanto, é um sistema de indexação, busca e teorização de dados não numéricos e não estruturados, ou, um pacote que permite analisar todo tipo de material passível de ser transformado em texto, como diários de campo, transcrições de entrevistas, grupos focais, programas de rádio ou televisão, reportagens jornalísticas, atas de reuniões, artigos, enfim, documentos que podem, inclusive, ser utilizados diretamente da Internet. ${ }^{4}$

Trata-se de uma tecnologia para estruturar informações que não tenham sido, necessariamente, pensadas e elaboradas para fins 
de pesquisa. Quando se fala na "objetividade" das variáveis em um banco de dados com informações quantitativas, não raro, omitese o trabalho qualitativo originário da construção e seleção das informações, das escalas, que nada mais foram que um processo de estruturação de dados. Um dos aspectos relevantes de programas como o NVivo, é o fato de eles agregarem à pesquisa qualitativa, aos seus moldes, sem importação ou cópia dos tratamentos analíticos para dados numéricos, um caráter metódico, de transparência nas decisões de pesquisa e, portanto, de "objetividade" nos limites em que ela se coloca para a pesquisa científica de um modo geral.

Em termos de funcionamento, o NVivo herdou o princípio básico do NUD*IST que é a codificação dos textos selecionados como material empírico visando posterior recuperação (code and retrieve). A codificação implica a criação de códigos, que podem ser comparados às pastas de um sistema operacional, nos quais serão armazenados índices de referência (indexadores) que se vinculam às porções do texto que compõem o material empírico. Codificação, portanto, é sinônimo de indexação; é um processo. Os códigos, por sua vez, dizem respeito a categorias, dimensões de análise ligadas aos problemas e interesses de pesquisa. São "recipientes" que recebem um nome e, opcionalmente, uma definição. Em ambos os programas, os códigos são denominados nodes que, em conjunto, formam a index tree root, uma espécie de árvore em que os ramos correspondem às dimensões de análise dispostos de forma hierarquizada e relacional. ${ }^{5}$ Os nós podem ser criados antes do processo de codificação, a partir de uma lista de categorias pré-elencadas, ou ao longo dele, isto é, pode-se alimentar o sistema de códigos à medida que a leitura do material empírico suscite questões que não haviam sido previstas no plano original de análise (Richards 1999; Teixeira \& Becker, 2001).

A codificação de uma passagem de texto em um nó - uma resposta numa entrevista, ou o posicionamento de um dos 
participantes de uma reunião transcrita em ata - não significa que este mesmo trecho de fala, ou ainda uma fração dele, não possa também ser codificado em outra dimensão analítica, ou seja, em outro nó. Isto porque o programa não trabalha de forma destrutiva, retirando do documento original a porção selecionada para codificação. Essa capacidade de registrar e armazenar codificações sobrepostas é, justamente, o que irá permitir resultados ricos de análise, com o auxílio de poderosas ferramentas de busca do material codificado.

Entre as diversas formas de empreender a codificação com o NVivo, a mais comum é a leitura direta dos documentos, na qual poderia ser aplicada a idéia de codificação em três planos proposta por Strauss e Corbin (1990): primeiramente uma análise linha a linha onde seriam examinadas palavras, frases e outras evidências, passando à análise de sentenças ou parágrafos, a fim de construir uma categorização a respeito destes blocos e, por último, uma análise do documento como um todo. Outra possibilidade é a busca automática por palavras ou padrões léxicos, que oferece, por um lado, a vantagem da velocidade, principalmente quando são utilizadas grandes massas de dados, mas por outro lado, pode levar a uma codificação dispersa. A decisão por uma ou outra forma de empreender a codificação dependerá de fatores que dizem respeito às decisões do pesquisador acerca de quando parar ou seguir no processo de refinamento das informações. É possível, por exemplo, usar as buscas automáticas de texto para recolher um primeiro volume de parágrafos e sentenças que então serão lidos mais cuidadosamente. Tanto no caso do processo de codificação, como na condução das buscas ou outros mecanismos visando à análise, a estratégia mais adequada vai depender em muito de fatores externos ao funcionamento do programa, como o tipo de material utilizado, os objetivos da pesquisa, prazos etc. O fato é que não existe fórmula pré-concebida para a condução de uma pesquisa com CAQDAS e os programas, para o bem da pesquisa e dos pesquisadores, têm oferecido cada vez mais flexibilidade. 
A análise de dados qualitativos com o NVivo foi elevada a uma dimensão superior em relação ao simples code and retrieve, pois, à análise das informações qualitativas provenientes da codificação do texto, o programa acrescentou algo comparável às variáveis de um banco de dados, chamado attributes. Com os atributos, tornou-se possível reunir, por exemplo, informações sociodemográficas dos entrevistados à base de dados sem a necessidade de codificação. Em outras palavras, para fins de análise, variáveis categóricas ou númericas provenientes de um banco de dados externo poderiam ser importadas e fazer parte dos critérios de busca e filtragem das falas codificadas dos entrevistados. Este recurso não estava presente no NUD*IST, o que tornava necessário criar nós (nodes) para sexo, idade, escolaridade etc. no sistema de índices (index tree) e, depois, codificar inteiramente os documentos de acordo com cada uma destas características.

\section{Uma nova síntese de programas para análise qualitativa: o caso do Nvivo 7}

Com a versão 7 do NVivo, lançada no primeiro semestre de 2006, a fabricante QSR International aposentou definitivamente o NUD*IST. ${ }^{6}$ As funcionalidades dos antecessores NUD*IST 6 e NVivo 2 foram aperfeiçoadas e colocadas em um só pacote, que, adicionalmente, apresentou ferramentas inovadoras para a organização, tratamento e análise dos dados, bem como para a representação gráfica dos resultados.

Embora os grandes vetores de gerenciamento das informações tenham sido mantidos (documentos, nós e atributos), algumas denominações foram alteradas e os caminhos para os recursos sofreram alterações significativas ocasionadas pela nova organização visual. As mudanças cumprem um propósito importante desta nova fase do programa, afinada com o momento propício que vive a 
análise de dados qualitativos auxiliada por computador após mais de 25 anos de desenvolvimento.

Trata-se, nas palavras de Lyn Richards (2006b), de "normalizar" a operacionalidade desses pacotes, ou seja, de aproximar seu manejo daqueles programas com os quais os usuários já têm certa familiaridade, particularmente os integrantes do Microsoft Office. Não é à toa que o layout do NVivo foi bastante aproximado ao do Outlook $^{7}$ (Figura 1).

\section{Figura 1 - Visão geral do NVivo 7}

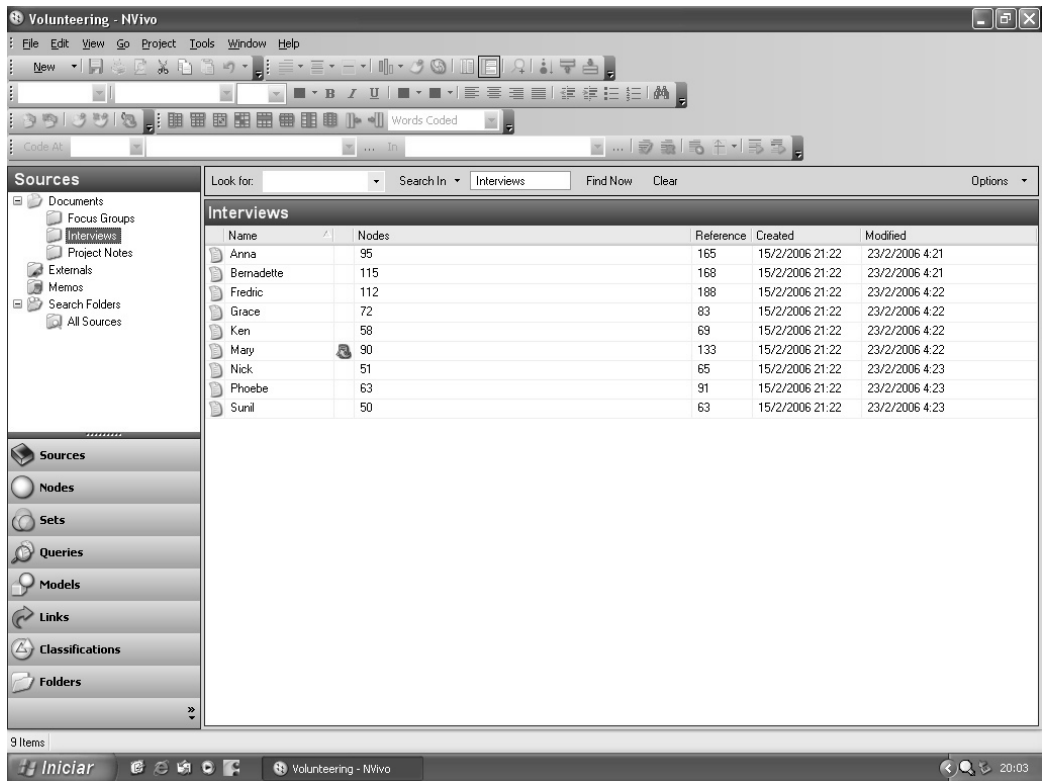

Outro aspecto importante do NVivo, presente desde suas versões anteriores, é a sua capacidade de permitir o trabalho em grupo, fornecendo um dispositivo adicional (o QSR Merge, vendido separadamente) que possibilita fundir em um só arquivo dois ou mais projetos, com seus códigos, documentos e atributos trabalhados 
separadamente. Isto facilita sobremaneira não só o processo de construção da base de dados, pela possibilidade de dividir tarefas como importação de documentos e codificação, mas também o controle dos resultados, já que o programa registra os passos e decisões de pesquisa em descrições de nós, memos, ou codificações automáticas das buscas, que podem depois ser comparados e afinados. Na versão 7, esta ferramenta está incorporada ao pacote, não mais como um elemento acessório e opcional.

A aposta no trabalho em redes e grupos de pesquisadores constitui um elemento importantíssimo da nova geração do NVivo e dos CAQDAS, mas talvez só venhamos a ter uma noção mais concreta de suas repercussões daqui a alguns anos, embora sempre possa representar perigo a tentação positivista de acúmulo de informações. De todo modo, coloca-se a possibilidade de formação de bases de dados qualitativos a partir de pesquisas desenvolvidas por grupos de pesquisa, nos moldes daquilo que já acontece há mais tempo com os dados numéricos e estruturados, ou, como mais comumente são chamados, dados quantitativos.

Essa característica tem reflexos no processo de produção de conhecimento nas Ciências Sociais à medida que a difusão do conhecimento acerca destas tecnologias da informação permite a circulação de um modo muito mais eficiente e transparente não só dos dados, mas dos métodos, das decisões de pesquisa, tornando mais acessível tudo aquilo que até então ficava relativamente restrito ao pesquisador que empreendia a investigação — suas notas, memórias, fichas coloridas e transcrições marcadas a canetas hidrocor e guardadas em caixas de sapato.

Claro está que esses programas não são meras ferramentas ou instrumentos técnicos, como papel e caneta. São tecnologias informacionais, posto que suas elaborações implicaram a racionalização e um complexo contato de idas e vindas acerca do processo de pesquisa em ciências humanas que, em última instância, na sociedade atual, é a análise de informações. 
$\mathrm{Na}$ utilização em investigações, na "construção da viagem inversa" da pesquisa social, de acordo com Tavares dos Santos 1989, essas tecnologias mediadas e contrapostas por orientações metodológicas e teóricas, acabam por transformar-se em metodologias, pois alteram o modo como o pesquisador se relaciona com os dados em termos de alcance, profundidade, capacidade de vigilância e mesmo possibilidade de invenção de estratégias inovadoras para a construção do conhecimento.

A tecnologia da informação é uma inteligência social coletiva com a qual interagimos. Neste sentido, o uso das novas tecnologias da informação tem efeito não apenas sobre algumas tarefas, mas sobre o modo de pensar, de conhecer, de aprender o mundo (Santos, 2001).

O surgimento de uma Sociologia Informacional, nos moldes apontados por Tavares dos Santos (2001), talvez tenha, de fato,

se iniciado. É difícil ainda precisar seus contornos, entretanto a constituição de coletividades científicas informacionais aponta para a emergência de um novo padrão de trabalho nas ciências sociais (Santos \& Baumgarten, 2005)

A seguir apresentaremos alguns dos desafios e possibilidades que se colocam para as Ciências Sociais e para a compreensão e desenvolvimento de redes a partir da emergência das novas tecnologias informacionais.

\section{Tecnologias informacionais e os desafios para as ciências sociais: centros de atividades sociológicas e informacionais}

$\mathrm{Na}$ intersecção entre tecnologias informacionais e Ciências Sociais surgem importantes questões: como migrar uma qualificada herança da pesquisa pré-digital para um novo ambiente midiático 
em rede digital sem maiores perdas? Partindo da idéia de que essa migração deve se realizar sob a rendição da memória do conhecimento preso às metodologias pré-digitais para uma integração complexa com os ambientes digitais, como devemos proceder? (Lima, 2005, p. 249).

Para que essas questões possam ser superadas, é necessário que a Sociologia passe por uma reformulação profunda, caracterizada por uma aproximação mais simbiótica e intensa com a teoria e as aplicações da informação digital, viabilizando uma abordagem transdisciplinar do social e de suas metodologias de tratamento informacional. ${ }^{8}$

Essa reformulação não deve se ater apenas aos programas avançados de pós-graduação em Sociologia, mas deve se fazer presente na gênese da formação dos graduandos, as novas gerações de sociólogos, implicando novas integrações de conteúdos formativos e metodológicos em uma complexa aprendizagem investigativa.

Trata-se de redesenhar a perspectiva de produção e investigação sociológica de competência múltipla, tanto de domínio teórico como aplicado também em ambientes propícios à experimentação, e, também, de enfatizar novos processos de aprendizagem e de estímulos inovadores à descoberta de conhecimento, ao ensino da investigação e à produção de conhecimento com menos consumo abstrato de teorias. A seguir, descrevemos estratégias de constituição de redes que se têm demonstrado úteis para encaminhar essa problemática.

Uma abordagem aplicada que pode ser importante para enfrentar a questão da implantação de projetos de múltipla competência sociológica encontra-se no uso adequado da teoria de redes em base de grafos, ${ }^{9}$ que aponta para constituição no interior dessas redes, de Centros de Atividades. ${ }^{10}$ Vejamos, então, o que seria um centro de atividades em agregações complexas de redes. 
Começaremos descrevendo um rápido caso. Em fevereiro de 2000, um hacker conhecido pelo apelido de MafiaBoy conseguiu paralisar alguns dos maiores sites do mundo, incluindo Yahoo, Amazon e eBay. Essa ação instaurou o caos na Internet, principalmente nos Estados Unidos. O ataque mobilizou o FBI, que saiu em busca daquele que havia derrotado empresas que contam com os melhores especialistas em segurança do mundo.

O que parecia trabalho de profissional acabou revelando-se a "brincadeira" de um garoto canadense de quinze anos e a casa de seus pais foi o local de onde ele comandou o ataque de amador, realizado com softwares gratuitos à disposição de qualquer um que tenha uma conexão com a Internet. Isso demonstra que mesmo uma rede de agregação complexa como a World Wide Web é capaz de absorver facilmente falhas aleatórias, como um site que saiu do ar, mas está fadada ao desastre se tiver de enfrentar um ataque dirigido.

A dificuldade está justamente em uma peculiaridade das redes, que foi descoberta por MafiaBoy. Se realizarmos uma simulação num computador sobre os links $d a W e b$, veremos que alguns poucos sites (como Amazon, Yahoo e eBay) funcionam como centros de atividade. Encontraremos milhares de outras páginas da Internet apontando para elas e milhares de pessoas tentando acessar esses sites ao mesmo tempo. Tirar algumas delas do ar, como fez o MafiaBoy, simplesmente paralisa a rede.

Esse caso gerou uma série de estudos sobre outros fenômenos de redes de agregação aleatória com tentativas de encontrar, nessas redes, a existência, ou não, de centros de atividade. Descobriuse, inclusive, que as redes e seus centros de atividades existem em toda parte no mundo contemporâneo, governando desde os relacionamentos humanos até a forma como as moléculas do nosso corpo se ligam. 
Um desses estudos tornou-se muito conhecido e foi publicado em livro pelo jornalista Malcolm Gladwell, da revista americana The New Yorker, sob o nome de O ponto de desequilíbrio, em 2002. Gladwell analisou, nesse livro, a habilidade das pessoas de diferentes grupos sociais criarem relações pessoais, e observou que cada grupo tinha algumas poucas pessoas com muitos amigos e conhecidos. Essas pessoas são os centros de atividade, também conhecidos como conectores. No entanto, os cientistas constataram que a própria natureza segue essas mesmas leis das redes criadas pelos homens com conectores, que são nós com um número anormalmente grande de links e que estão presentes em vários sistemas complexos desde a pequena célula viva até a macro organização das sociedades humanas (Barabãsi, 2002).

Atualmente, os estudos de relacionamentos em redes têm demonstrado que essas diversas redes seguem um fenômeno como se o mundo fosse pequeno - uma frase que se diz quando encontramos uma pessoa pela primeira vez num lugar inesperado e descobrimos que ela é amiga de um amigo nosso. Segundo cálculos de AlbertLászlo Barabãsi (2002, p. 36), uma página da Web está a somente 19 cliques de qualquer outra, ainda que uma esteja sediada no Japão e a outra em Honduras. A explicação para o fenômeno é simples. Preferimos nos conectar a quem já é mais conectado. Páginas da Web com mais links têm também uma chance maior de receberem ainda mais links, pois já são conhecidas. Atores de Hollywood que já participaram de vários filmes têm mais probabilidades de fazerem novos filmes. Hoje está provado que, independentemente de ser uma rede de computadores, moléculas ou pessoas, a popularidade atrai. As descobertas de Barabãsi e seus colegas sobre redes são parte de uma revolução que vai mudar nosso entendimento do mundo.

Se até o século XX vivemos uma era de descobertas de como entendemos e usamos as propriedades individuais de objetos tão diferentes como moléculas, aviões e sites, a partir do século XXI 
descobriremos como as propriedades individuais de todos esses objetos e fenômenos se relacionam.

Há, hoje, espaço para estudos novos sobre a interação entre cada um dos componentes das redes sociais e na vida em sociedade. Por exemplo, as pesquisas sobre epidemias sociais têm demonstrado que a rede de relações sexuais funciona dentro do mesmo padrão de centros de atividade. Nela, alguns poucos têm centenas de parceiros sexuais (conectores), enquanto a maioria tem relações sexuais somente com uma ou outra pessoa. No caso de uma doença sexualmente transmissível, são esses conectores os primeiros a serem infectados e também os responsáveis por disseminar a doença para muitas outras pessoas.

Essas descobertas estão relacionadas com desenvolvimentos tecnológicos e questões sociais e econômicas, tais como o surgimento, nas últimas décadas, de computadores de mesa a preços acessíveis, capazes de fazer a montanha de cálculos necessários para se entender o que se passa dentro das redes. Antes disso, até se sabia que as redes existiam, mas era impossível entendê-las, dada a sua complexidade; por outro lado, a própria Matemática nos auxilia a entender os atratores das redes, por meio de operações de cálculos relacionais, que constituem o campo da matemática conhecido como grafos.

Grafos são redes formadas por nós conectados por arestas ou arcos. Já existe uma literatura considerável sobre algoritmos para grafos, que são uma parte importante da matemática discreta. Entretanto, o que nos interessa aqui é ressaltar que, para uma análise de agregação complexa em redes, faz-se necessário estabelecermos relações entre os dados, criando, no mínimo, um dicionário cujas chaves são os nós do grafo.

Em vista disso, a partir de uma rápida mineração pela $W e b$, encontramos, sem muito esforço, alguns centros de atividade em 
dupla competência na Sociologia (Sociologia e Informática) no Brasil. A seguir, alguns dos exemplos encontrados:

Na Unicamp encontramos o Portal das Ciências Sociais e Sociedade da Informação, que, conforme seus registros, opera como um centro de atividade de integração de cursos, conferências, listas de discussão, bibliotecas virtuais, legislação e pesquisas, os quais relacionam as ciências sociais com múltiplos temas informacionais, inclusive com temas especialistas, como o uso da inteligência artificial nas ciências sociais. ${ }^{11}$

Outro exemplo de um centro de atividade de dupla competência em Sociologia e Ciências Sociais está no Iuperj, que se caracteriza por migrar as linhas de trabalho consolidadas a partir de extensa produção acadêmica tradicional para o que os pesquisadores desse centro de atividade denominaram de Programa Institutos Virtuais, que é também patrocinado pela Fundação de Amparo à Pesquisa do Estado do Rio de Janeiro (Faperj).

Os pesquisadores do Iuperj possuem um grande acúmulo no uso de softwares integrados à pesquisa, principalmente quantitativos como o SPSS, e possuem tambem alguns Bancos de Dados Bibliográficos e Políticos significativos, como: a) Urbandata; b) Data Índice; c) DOXA - Laboratório de Pesquisas em Comunicação Política e Opinião Pública; d) Dados Eleitorais do Brasil. ${ }^{12}$

Na Universidade Federal de Minas Gerais (UFMG) encontramos outro importante exemplo de centro de atividades com dupla competência: Centro de Estudos de Criminalidade e Segurança Pública, conhecido como Crisp.

Voltado para a elaboração, acompanhamento de implementação e avaliação crítica de políticas públicas na área da justiça criminal, o Crisp é composto por pesquisadores dessa Universidade e de órgãos públicos envolvidos com o combate à criminalidade. Tem por objetivos facilitar ativamente a qualificação dos profissionais da 
área de segurança pública, e elaborar estudos e pesquisas aplicadas e metodológicas, de alta qualidade técnica, que procurem enfocar problemas e questões de interesse para o combate à criminalidade. As atividades do Crisp também se caracterizam pela organização de bases de dados criminais de interesse para as organizações da justiça criminal brasileira.

Merece destaque a organização de dados pontuais de crimes na cidade de Belo Horizonte, uma iniciativa inédita no Brasil e que se tornou referência em análises espaciais de dupla competência sobre a criminalidade e o mapeamento de crimes. Nos últimos anos, o Crisp tornou-se um centro de atividades com um papel cada vez mais importante como órgão de assessoria, de suporte técnico e acadêmico, e de formação para organizações do sistema de justiça criminal.

O Crisp realizou alguns importantes e inovadores produtos informacionais derivados da dupla competência sociológica, como:

a) atlas da criminalidade de Belo Horizonte - diagnósticos, perspectivas e sugestões de programas de controle;

b) atlas da criminalidade de Minas Gerais;

c) diagnóstico da criminalidade violenta na região metropolitana de Belo Horizonte: estudo espaço-temporal do período 1986-2001;

d) organização de base de dados para a Delegacia de Crimes contra a Vida;

e) implicações socioeconômicas da violência em Belo Horizonte: os centros de saúde;

f) conselhos comunitários de segurança pública: avaliação, análise e acompanhamento do policiamento comunitário em Belo Horizonte; 
g) mapa da distribuição e uso de drogas em Minas Gerais;

h) análise do fluxo das ocorrências de homicídio no Sistema de Justiça;

i) pesquisa de vitimização em Belo Horizonte;

j) implicações socioeconômicas da violência em Belo Horizonte: as escolas de Belo Horizonte;

k) criação de uma biblioteca de sub-rotinas de análise estatística integrada ao Sistema de Informação da PM/MG;

1) análise no efeito do tamanho das cidades no comportamento das taxas de crime no Estado de Minas Gerais;

m) detecção de clusters (agregação de dados-fenômenos);

n) software bayes.

A força significante desse centro de atividade com dupla competência é a utilização nos trabalhos de pesquisa do software bayes. Esse programa permite um suporte informacional e mimético espacial utilizando mapas com o método empírico bayesiano, que integra diferentes taxas desconhecidas derivadas de processos sociais e ambientais subjacentes que afetam a região em estudo. Dessa forma, é possível, mediante modelos probabilísticos, determinar as variações das taxas de crime.

Também esse centro de atividades disponibiliza alguns de seus cursos em plataformas para cursos à distância com apoio de redes $W e b$. Além disso utilizam vídeo-aulas e outros recursos de apoio aos cursos à distância.

Por fim, encontramos nesse centro de atividade um volumoso banco em base de dados sobre homicídios no Brasil - Atlas Brasil. A base de dados do projeto, possui, como unidade de análise, os 
municípios brasileiros e contém a relação dessas localidades com seus respectivos números brutos de homicídios, as taxas corrigidas e a população para o período entre 1980 e 2000.

O principal objetivo desse banco de dados é permitir a análise da distribuição dos homicídios no Brasil levando em conta as taxas de homicídio corrigidas pelo tamanho populacional dos município; os tipos de armas utilizadas pelos agressores e o perfil das vítimas, considerando variáveis como raça, instrução, sexo, estado civil, faixa etária e local onde ocorreu o crime.

Esse banco foi alimentado também por dados secundários do Datasus - banco de dados construído pelo Sistema Único de Saúde -, bem como com informações do IBGE - Instituto Brasileiro de Geografia e Estatística. No Datasus foram coletados os números brutos de homicídios registrados no Brasil, não tendo sido feitas as distinções entre homicídios culposos e dolosos, enquanto as informações do IBGE referem-se ao levantamento das micro e mesorregiões, municípios e Estados. ${ }^{13}$

Um último exemplo da existência de centros de atividade com dupla competência a destacar é a Fundação de Economia e Estatística (FEE), no Rio Grande do Sul. Trata-se de uma instituição uma larga cultura de tratamento informacional quantitativo e que dispõe de uma vasta biblioteca virtual de sua produção de índices, mapas e dados que podem ser encontrados em CDs, teses, documentos diversos, boletins, Carta de Conjuntura, Informe PED (mensal), Informe PED (anual), Indicador Mensal do Comércio Varejista (IMCV), revistas (Ensaios FEE, Indicadores Econômicos FEE, Mulher e Trabalho, Metrópoles: enfoque sobre a problemática habitacional). Também se encontram atualizações sistemáticas de dados sobre PIB, população, emprego/desemprego, bem como do IMCV.

No site da FEE há, ainda, uma Biblioteca Virtual do Rio Grande do Sul (BVRS). Trata-se de uma rede de bibliotecas do setor público 
do Estado do Rio Grande do Sul, que é administrada pela FEE. Nela, o usuário acessa múltiplos dados bibliográficos e realiza pesquisas por autores, títulos e assuntos, em uma ou em todas as bibliotecas participantes, assim como é possível baixar registros bibliográficos (download) para formação de bases de dados locais, desde que as bases utilizem o padrão CDS/ISIS e o formato MARC. ${ }^{14}$

Esses exemplos servem apenas para indicar que é possível, numa rápida navegação pela Internet, encontrarmos alguns poucos, mas expressivos, centros de atividade com dupla competência em Ciências Sociais e Ciências da Informação no Brasil.

\section{Conclusão}

Como vimos, a informação computadorizada está conquistando cada vez mais um espaço de significação reflexiva pela sua potencialidade mediadora diante da realidade e, inclusive, na construção do próprio saber.

A informação re-significada pela nova mídia reflexiva digital apresenta-se cada vez mais, como um resultado de pasteurização do mundo realizada por mediações de estruturas semi-reflexivas, o que gera, também progressivamente, uma complexa sintetização digital da realidade. Um desafio cada vez maior sobre nossa capacidade analítica para continuarmos no difícil caminho da qualidade complexa da produção do conhecimento sociológico é aprender a escapar dos atalhos "facilitadores" oferecidos pelo determinismo tecnológico e, também, do embotamento movido pela cegueira conservadora que vê na tecnologia um inimigo.

Assim, por um lado, parece importante lembrar que as possibilidades de replicação das atividades rotineiras do processamento lógico do cérebro humano em máquinas cognitivas e, também, a tecnologia, que permite amplificarmos nossas resso- 
nâncias sensórias em sofisticados suportes ambientalizados por sistemas digitais de simulação e interação, são criações humanas. Por outro lado, a infra-estrutura reflexiva de informação e de comunicação digital, mesmo sendo capaz de replicar uma reflexividade mimética (representação imitada), não é sinônimo de conhecimento complexo. Sequer trata-se de uma nova modulação de conhecimento. A rede digital de comunicação e de informação computada não passa de uma mera invenção potente de redução de complexidade (Lima, 2005, p. 242).

Reafirmamos que, ao dar conta de modo extremamente preciso da redução da complexidade da realidade vital, as novas tecnologias de informação e comunicação possibilitam, em contrapartida, uma gama quase infinita de amplificadores cognitivos a serem exercidos em simbiose do mundo vital com o mundo digital, facilitando extremamente a produção do conhecimento na sociedade contemporânea.

Esse conjunto de questões aponta para a inevitabilidade do ensino de um conhecimento transdisciplinar, envolvendo as Ciências Sociais e as Ciências da Computação, e a incorporação do paradigma da complexidade na prática sociológica (Santos \& Baumgarten, 2006).

$\mathrm{Na}$ época de incertezas em que vivemos, o fazer científico e o conhecimento que dele resulta apenas nos indicam caminhos possíveis. A ciência pode ser uma técnica social que permite ver as potencialidades do real e agir com base nesse olhar. De acordo com essa perspectiva, a partir do feixe de possíveis que a realidade nos apresenta, é válido pensar utopias que superem as conquistas da modernidade e incorporem o domínio coletivo e consciente das ciências, das técnicas, das escolhas de produção, de distribuição e de consumo de bens materiais e não materiais. 


\section{Notas}

1 Tecnociência - sistema de ações eficientes, baseadas em conhecimento científico. Essas ações se orientam tanto para a natureza quanto para a sociedade, visando transformar o mundo, para além de descrever, predizer, explicar, compreender. A tecnociência implica a empresarialização da atividade científica e, sendo um fator relevante de inovação e de desenvolvimento econômico, passa a ser também um poder dominante na sociedade, tendendo, sua prática, ao segredo e à privatização (Echeverría, 2003).

2 Para mais informações sobre pesquisa qualitativa auxiliada por computador, como comparações entre softwares disponíveis e sua aplicabilidade, convém consultar o site da CAQDAS Networking Project na internet: http://caqdas.soc.surrey.ac.uk

3 Em 1999, a QSR International, fabricante do NUD*IST lançou a primeira versão do NUD*IST Vivo, ou apenas NVivo como passou a ser chamado.

4 O formato para utilização com o NUD*IST era necessariamente texto sem formatação (txt). Já com o NVivo abriu-se a possibilidade de trabalhar com texto formatado ( $\mathrm{rtf}$ ) desde que sem elementos gráficos (imagens e tabelas). A versão 7 do NVivo já importa sem restrições documentos do Microsoft Word (doc).

5 O NUD*IST tinha justamente uma árvore como logomarca.

6 A versão 1.1 do NVivo foi lançada simultaneamente à versão 5 do NUD*IST.

7 A proximidade do NVivo com os produtos da Microsoft não ficou somente em aspectos gráficos. O programa passou a utilizar protocolos SQL (Server Query Language) para os procedimentos internos de indexação e buscas, o que deve ter contribuído para a QSR tornar-se "Microsoft Gold Partner".

8 Para uma abordagem sobre o uso das metodologias informacionais na Sociologia no Brasil, ver: Lima (2004).

9 A teoria e técnica estatística de grafos é o ramo da Matemática que estuda as propriedades de grafos. Um grafo é uma derivação da Matemática 
expressa num conjunto de pontos, chamados vértices (ou nodos), conectados por linhas, chamadas de arestas (ou arcos). Dependendo da aplicação, as arestas podem ter ou não direção, podem ou não estar ligando um vértice a ele próprio e vértices e/ou arestas podem ter um peso (numérico) associado. Se as arestas têm uma direção associada (indicada por uma setinha na representação gráfica), temos um grafo direcionado ou dígrafo.

10 Para maiores esclarecimentos do conceito de Centro de Atividades, ver: Lima (2004; e, principalmente, 2005, p. 249-259: “As redes têm centros: são centros de atividades sociológicas e informacionais").

11 http://www.bibli.fae.unicamp.br/hz144/portal.htm (acesso em: 19 de julho de 2006).

12 http://www.iuperj.br/ (acesso em: 19 de julho de 2006).

13 Para maiores informações ver: http://www.crisp.ufmg.br/ (acesso em: 19 de julho de 2006).

14 Veja: http://www.fee.tche.br/sitefee/pt/content/capa/index.php (acesso em: 19 de julho de 2006).

Society and knowledge: new technologies and challenges for research and production of knowledge on Social Sciences

Abstract; This article discusses some questions on relations between society and knowledge, approaching issues linked to society of information and interdisciplinarity (networks), associated to advances on information and communication technologies. Based on those relations, it discusses specifically the development of informational methodologies and the possibilities and challenges emerging from them for research and production of knowledge on Social Sciences and for the understanding and development of information and knowledge networks.

Keywords: information technologies, knowledge, information, informational technologies 


\section{Referências}

BACHELARD, Gaston. Le matérialisme rationnel. Paris: PUF, 1990. ( $1^{\mathrm{a}}$ edição: 1953$)$. . Le nouvel sprit scientifique. Paris: PUF, 1984. (1ª edição: 1934).

BARABÃSI, Albert-László. Linked: the new science of networks. New York: Plume Books, 2002.

BARRY, Cristine. Choosing Qualitative Data Analysis Software: Atlas/TI and NUD*IST Compared. Sociological Research Online, v. 3, n. 3, 1998. Disponível em: <http://www.socresonline.org.uk/socresonline/3/3/4.html >. Acesso em: 22 jan. 1999.

BAUMGARTEN, M. Sociedade e conhecimento: ordem, caos e complexidade. Sociologias, v. 8, n. 15, p. 16-23, 2006.

BIBLIOTECA DIGITAL DA UFRGS. Disponível em: < http://www.biblioteca.ufrgs.br/bibliotecadigital>.

CAQDAS Networking Project. Disponível em: http://caqdas.soc.surrey. ac.uk.

CENTRO DE ESTUDOS DE CRIMINALISTICA E SEGURANÇA PÚBLICA (Crisp). Disponível em: <http://www.crisp.ufmg.br $>$ Acesso em: 19 jul. 2006.

ECHEVERRÍA, Javier. Introdução à metodologia da ciência. Coimbra: Almedina, 2003.

FUNDAÇÃO DE ECONOMIA E ESTATÍSTICA (FEE). Disponível em: $<$ http://www.fee.tche.br/sitefee/pt/content/capa/index.php $>$ Acesso em: 19 jul. 2006.

GAYA, A.; TORRES, L. Do conhecimento científico ao saber pedagógico. In: BENTO, J.; MARQUES, A.; PRISTA, A. Atividade física e desporto, fundamentos e contextos. Lisboa: Caoluste Gulbenkyan, 2003. p. 44-54.

GLADWELL, Malcom. O ponto de desequilíbrio. Rio de Janeiro: Rocco, 2002. 
GRAMSCI, A. A concepção dialética da história. Rio de Janeiro: Civilização Brasileira, 1978.

HERMAN, J. Les langages de la Sociologie. Paris: P.U.F., 1983. (Coll. Que sais-je?).

IUPERJ. Disponível em: http://www.iuperj.br. Acesso em: 19 jul. 2006.

KELLE, Udo. Capabilities for theory building \& hypothesis testing. In: Software for Computer Aided Qualitative Data Analysis. Data Archive Bulletin, n. 65, 1997. Disponível em: <http://www.soc.surrey. ac.uk/caqdas/kelle.doc>. Acesso em: 15 Abr 1999.

LASTRES, H. M. M.; ALBAGLI, S. (Orgs.). Informação e globalização na era do conhecimento. Rio de Janeiro: Campus, 1999.

LESSARD-HÉBERT, M. et al. Investigação qualitativa: fundamentos e práticas. Lisboa: Instituto Piaget, 1994.

LÉVY, Pierre. Cibercultura. São Paulo: Editora 34, 1999.

LIMA, Gilson. A reconstrução da realidade com a informação digital: a emergência da dupla competência sociológica. Tese (Doutorado em Sociologia) - Universidade Federal do Rio Grande do Sul, Porto Alegre, 2004. Disponível em: <http://www.biblioteca.ufrgs. $\mathrm{br} / \mathrm{bibliotecadigital} />$.

. Nômades de pedra: teoria da sociedade simbiogênica contada em prosas. Porto Alegre: Escritos, 2005.

MACIEL, M. L. Hélices, sistemas, ambientes e modelos: os desafios teóricos à Sociologia de C\&T. Sociologias, Porto Alegre, n. 6, 2001.

MANGABEIRA, Wilma: LEE; Raymond; FIELDING, Nigel. Padrões de adoção, modos de uso e representações sobre tecnologia: usuários do CAQDAS no Reino Unido em meados da década de 90. Sociologias, Porto Alegre, v. 3, n. 5, p.20-57, 2001.

MORIN, E. O método 3: o conhecimento do conhecimento. Porto Alegre: Sulina, 1999. (edição original: 1986). 
NUNES, A. Um discurso sobre as ciências 16 anos depois. In: SANTOS, B. de Sousa. Conhecimento prudente para uma vida decente. Porto, Portugal: Afrontamento, 2003. p. 57-80.

PORTALDAS CIÊNCIAS SOCIAIS E SOCIEDADEDA INFORMAÇÃO. Disponível em: <http://www.bibli.fae.unicamp.br/hz144/portal. htm>. Acesso em: 19 jul. 2006.

RICHARDS, Lyn. An opinionated account of qualitative computing. Disponível em: <http://www.lynrichards.org/ Computing\%20Opinion.htm>. Acesso em: 25 abr. 2006a. . Moving up: how research and teaching will change with NVivo 7. Disponível em: <http://www.qual-strategies.org/previous/2005/ papers/RichardsL/files/Richards, L. pps $>$. Acesso em: 30 set. 2006b.

. Using NVivo in qualitative research. Victoria: QSR International, 1999.

SANTOS, Boaventura de Sousa. A crítica da razão indolente: contra o desperdício da experiência. São Paulo, Cortez, 2000.

. A gramática do tempo: para uma nova cultura política. Porto, Portugal: Almedina, 2006.

SANTOS, José Vicente Tavares dos. As possibilidades das metodologias informacionais nas práticas sociológicas: por um novo padrão de trabalho para os sociólogos do Século XXI. Sociologias, Porto Alegre, v. 3, n. 5, p. 114-146, 2001.

. A construção da viagem inversa: ensaio sobre a investigação nas ciências sociais - anexo. Cadernos de Sociologia, v. 1, n. 1, abr. 1989.

SANTOS, José Vicente Tavares dos; BAUMGARTEN, M. Sociedade da informação: as metodologias inovadoras no ensino contemporâneo da Sociologia: para onde vai a pós-graduação no Brasil? Bauru, EDUSC, v. 1, p. 215-243, 2005. 
STEHR, N. Knowledge societies. Londres: Sage, 1994.

STRAUSS, Anselm; CORBIN, Juliette. Basics of qualitative research: grounded theory procedures and techniques. London: Sage, 1990.

TEIXEIRA, Alex Niche; BECKER, Fernando. Novas possibilidades da pesquisa qualitativa via sistemas CAQDAS. Sociologias, Porto Alegre, v. 3, n. 5, p. 94-114, 2001.

VÉDRINE, H. As filosofias da história. Rio de Janeiro: Zahar, 1977.

VIRGÍNIO, A. Conhecimento e sociedade: diálogos impertinentes. Sociologias, Porto Alegre, v. 8, n. 15: p. 88-135, 2006. 